\title{
The First Line Treatment of Advanced or Metastatic BRAF Mutant Melanoma: A Network Meta-analysis
}

\author{
Zhenyi Yang \\ Fourth Affiliated Hospital of China Medical University \\ Wen Zhong \\ Fourth Affiliated Hospital of China Medical University \\ Ping Wen \\ Fourth Affiliated Hospital of China Medical University \\ Yixuan Luo \\ Fourth Affiliated Hospital of China Medical University \\ Chunli Wu ( $\nabla$ clwu@cmu.edu.cn ) \\ Fourth Affiliated Hospital of China Medical University
}

\section{Research Article}

Keywords: BRAF mutant melanoma, network meta-analysis, immunotherapy, targeted therapy

Posted Date: May 7th, 2021

DOI: https://doi.org/10.21203/rs.3.rs-439425/v1

License: (c) (i) This work is licensed under a Creative Commons Attribution 4.0 International License. Read Full License 


\section{Abstract}

Purpose: The treatments for advanced or metastatic BRAF mutant melanoma are flourish, but the most effective treatment is unclear. Here, we conducted a network meta-analysis (NMA) in unresectable stage III or advanced (or metastatic) stage IV BRAF mutant melanoma patients to estimate the efficacy of various first line treatments.

Methods: A comprehensive search for RCTs in PubMed and EMBASE was conducted to January 2021. Randomized control trials of unresectable stage III or advanced stage IV BRAF mutant melanoma were eligible if not receive previously treatment. By a Bayesian network meta-analysis, the effectiveness of each treatment was estimated and ranked based on the odds ratio (OR) for Object response rate (ORR) and hazard ratio (HR) for Overall survival (OS).

Results: Eight trials enrolling 3272 patients were included. Combination dabrafenib and trametinib with pembrolizumab (HR: 0.37; $95 \%$ confidence interval [Cl]: 0.21-0.66; compared with dacarbazine) ranked as the best effective treatment for OS.

Conclusion: Combination pembrolizumab with trametinib and dabrafenib and combination atezolizumab with trametinib and dabrafenib appear more effective as first line treatments for unresectable stage III or advanced (or metastatic) stage IV BRAF mutant melanoma patients. Whereas, further RCTs are needed to complete the network.

\section{Introduction}

Approximate $40 \%$ to $60 \%$ of cutaneous melanoma patients carry BRAF mutation, which could constitutively activate the downstream signaling through the MAP kinase pathway and increase melanoma cells proliferation and survival.[1, 2] A latest randomized control trial (RCT) indicates a landmark OS rate of $34 \%$ after 5years by targeting this signaling pathway.[3] Combination BRAF and MEK inhibitors could increase melanoma antigens and involve in transporting CD8+ and CD4+ cells to melanoma.[4-7] Although this combination therapy leads to a considerable cancer response of 75\% in BRAF mutant melanoma patients,[8] most responses are short-lived.[9] Furthermore, patients quickly acquired resistance to it and resulted in relapse within months.[10-12] A three-year pooled analysis indicated that at least 70\% of patients experienced relapse or metastasis within the first 3 years of therapy.[13] Interestingly, we found an increased expression of PD-1 and PD-L1 in advanced or metastatic BRAF mutant melanoma patients who accept the treatment of BRAF inhibitors.[4] And anti-PD-1 immune checkpoint inhibitor is a vital coregulatory factor for down-regulation of T-cell activation.[14-16] Therefore, combination immune checkpoint inhibitors (ICls) and BRAF inhibitors may conduct a more effective treatment for those patients.

Additionally, immune checkpoint inhibitors, BRAF inhibitors and MEK inhibitors all show vital therapeutic effectiveness in advanced or metastatic BRAF mutant melanoma patients.[10, 17-23] Immune checkpoint inhibitors provide more durable responses but their response rates are relatively lower.[24] Therefore, a triple combination therapy of MEK inhibitors, BRAF inhibitors and anti-PD-1 or anti-PD-L1 immune checkpoint inhibitors need to be conducted.[25, 26]

Presently, two randomized controlled trials indicated that triple combination therapy is more effective than combination MEK inhibitors and BRAF inhibitors.[27, 28] Therefore, we compared the efficacy of various treatments by a network meta-analysis and tried to find a best first-line treatment in advanced or metastatic BRAF mutant melanoma patients.

\section{Methods}

\section{Literature search}

This systematic review and network meta-analysis of RCTs, registered on the PROSPERO database (CRD42021234924) and followed the Preferred Reporting Items for Systematic Reviews and Meta-analyses for Network Meta-analysis (PRISMA-NMA) reporting guideline,[29] was updated to January, 2021.

Treatments include combination atezolizumab with cobimetinib and vemurafenib, combination vemurafenib and cobimetinib, combination pembrolizumab with dabrafenib and trametinib, combination dacarbazine and selumetinib, combination dabrafenib and trametinib, dabrafenib monotherapy, vemurafenib monotherapy, dacarbazine monotherapy. Two endpoints were all efficacy that measured by objective response rate (ORR), overall survival (OS). A search on PubMed and Embase, following the algorithm: "(BRAF mutation) AND (melanoma)", was conducted by Mr. Yang and Mrs. Zhong. The conflicts and uncertainties were finally resolved by Mrs. Wu.

The following inclusion criteria were used: 1) neoplasm: unresectable stage III and advanced or metastasis stage IV BRAF mutant melanoma;

2) most of patients (>80\%) did not receive treatment before; 3 ) study design: RCTs reporting on ORR and OS; No language restriction was applied. If there are multiple publications of the same RCTs, the latest data was included. 


\section{The Risk of bias}

The assessment of the risk of bias was conducted by Mr. Yang and Mrs. Zhong with the Cochrane Risk of bias tool.[30] All RCTs were assessed by three grades: high risk, unclear risk, or low risk. The extraction of data was carried out by Mr. Yang and Mrs. Zhong and independently verified by Mrs. Wu.

\section{Statistical analysis}

we conducted this NMA with R (R Project for Statistical Computing; version 3.6.2; gemtc package).[31] The OR and 95\% Cls were used to estimate ORR. The HR and 95\% Cls were used to estimate OS. For any comparison, an OR for ORR bigger than 1 or an HR for OS smaller than 1 means that the treatment was more effective. The heterogeneity between the comparisons was estimated by the l-squared statistic.

DIC was used for model selection. The chain of model was three. The adaptation was 10000 and model iteration was 100000 . Edge-splitting was used for the evaluation of inconsistency. Additionally, we ranked all outcomes by the probability.

\section{Results}

\section{Characteristics of All Trials}

14 articles containing 8 trials were included for subsequent analysis.[8, 12, 19, 27, 28, 32-40] Trails directly compared the following 8 treatments: combination atezolizumab with cobimetinib and vemurafenib, combination vemurafenib and cobimetinib, combination pembrolizumab with dabrafenib and trametinib, combination dacarbazine and selumetinib, combination dabrafenib and trametinib, dabrafenib monotherapy, vemurafenib monotherapy, dacarbazine monotherapy (Network plot, figure 1). The detailed description of all RCTs was showed in Table 1. All trials were two-arm trials. NMA for ORR (I-square. cons=0) and OS (I-square. cons $=0)$ show no heterogeneity and absent inconsistency.

Table. 1

\section{Characteristics of included studies}




\begin{tabular}{|c|c|c|c|c|c|c|c|c|}
\hline trail name & treatment & masking & phase & $\begin{array}{l}\text { participants, } \\
\text { NO. }\end{array}$ & $\begin{array}{l}\text { male, } \\
(\%)\end{array}$ & $\begin{array}{l}\text { Median } \\
\text { age, } \\
\text { years } \\
\text { (range) }\end{array}$ & $\begin{array}{l}\text { OR } \\
\text { No. } \\
\text { (total } \\
\text { No.) }\end{array}$ & $\begin{array}{l}\text { OS, } \\
\text { HR } \\
(95 \% \mathrm{Cl})\end{array}$ \\
\hline \multirow[t]{2}{*}{$\begin{array}{l}\text { IMspire150 } \\
\text { (NCT02908672) }\end{array}$} & vemurafenib+cobimetinib+atezolizumab & $\begin{array}{l}\text { double- } \\
\text { blind }\end{array}$ & 3 & 256 & 59 & $\begin{array}{l}54 \cdot 0 \\
(44 \cdot 8- \\
64 \cdot 0)\end{array}$ & $\begin{array}{l}169 \\
(255)\end{array}$ & \multirow[t]{2}{*}{$\begin{array}{l}0.85 \\
(0.64- \\
1.11)\end{array}$} \\
\hline & vemurafenib+cobimetinib+placebo & & & 258 & 58 & $\begin{array}{l}53.5 \\
(43.0- \\
63.8)\end{array}$ & $\begin{array}{l}160 \\
(246)\end{array}$ & \\
\hline \multirow[t]{2}{*}{$\begin{array}{l}\text { KEYNOTE-022 } \\
\text { (NCT02130466) }\end{array}$} & dabrafenib+trametinib+pembrolizumab & $\begin{array}{l}\text { double- } \\
\text { blind }\end{array}$ & 2 & 60 & 55 & $\begin{array}{l}54 \cdot 0 \\
(18.0- \\
82.0)\end{array}$ & $\begin{array}{l}38 \\
(60)\end{array}$ & \multirow[t]{2}{*}{$\begin{array}{l}0.64 \\
(0.38- \\
1.06)\end{array}$} \\
\hline & dabrafenib+trametinib+placebo & & & 60 & 60 & $\begin{array}{l}58.0 \\
(21.0- \\
83.0)\end{array}$ & $\begin{array}{l}43 \\
(60)\end{array}$ & \\
\hline \multirow[t]{2}{*}{$\begin{array}{l}\text { coBRIM } \\
\text { (NCT01689519) }\end{array}$} & vemurafenib+cobimetinib & triple-blind & 3 & 247 & 59 & $\begin{array}{l}56.0 \\
(23.0- \\
88.0)\end{array}$ & $\begin{array}{l}172 \\
(247)\end{array}$ & \multirow[t]{2}{*}{$\begin{array}{l}0.70 \\
(0.55- \\
0.90)\end{array}$} \\
\hline & vemurafenib+placebo & & & 248 & 56 & $\begin{array}{l}55.0 \\
(25.0- \\
85.0)\end{array}$ & $\begin{array}{l}123 \\
(248)\end{array}$ & \\
\hline \multirow[t]{2}{*}{$\begin{array}{l}\text { COMBI-d } \\
\text { (NCT01584648) }\end{array}$} & dabrafenib+trametinib & $\begin{array}{l}\text { quadruple- } \\
\text { blind }\end{array}$ & 3 & 211 & 53 & $\begin{array}{l}55.0 \\
(22.0- \\
89.0)\end{array}$ & $\begin{array}{l}144 \\
(210)\end{array}$ & \multirow[t]{2}{*}{$\begin{array}{l}0.75 \\
(0.58- \\
0.96)\end{array}$} \\
\hline & dabrafenib+placebo & & & 212 & 54 & $\begin{array}{l}56.5 \\
(22.0- \\
86.0)\end{array}$ & $\begin{array}{l}116 \\
(211)\end{array}$ & \\
\hline \multirow[t]{2}{*}{$\begin{array}{l}\text { COMBI-v } \\
\text { (NCT01597908) }\end{array}$} & dabrafenib+trametinib & open-label & 3 & 352 & 59 & $\begin{array}{l}55.0 \\
(18.0- \\
91.0)\end{array}$ & $\begin{array}{l}226 \\
(351)\end{array}$ & \multirow[t]{2}{*}{$\begin{array}{l}0.69 \\
(0.53- \\
0.89)\end{array}$} \\
\hline & vemurafenib monotherapy & & & 352 & 51 & $\begin{array}{l}54.0 \\
(18.0- \\
88.0)\end{array}$ & $\begin{array}{l}180 \\
(350)\end{array}$ & \\
\hline \multirow[t]{2}{*}{$\begin{array}{l}\text { BRIM-3 } \\
\text { (NCT01006980) }\end{array}$} & vemurafenib monotherapy & open-label & 3 & 337 & 59 & $\begin{array}{l}56.0 \\
(21.0- \\
86.0)\end{array}$ & $\begin{array}{l}106 \\
(219)\end{array}$ & \multirow[t]{2}{*}{$\begin{array}{l}0.81 \\
(0.67- \\
0.98)\end{array}$} \\
\hline & dacarbazine monotherapy & & & 338 & 54 & $\begin{array}{l}52.0 \\
(17.0- \\
86.0)\end{array}$ & $\begin{array}{l}12 \\
(220)\end{array}$ & \\
\hline \multirow[t]{2}{*}{$\begin{array}{l}\text { BREAK-3 } \\
\text { (NCT01227889) }\end{array}$} & dabrafenib monotherapy & open-label & 3 & 187 & 60 & $\begin{array}{l}53.0 \\
(22.0- \\
93.0)\end{array}$ & $\begin{array}{l}93 \\
(187)\end{array}$ & \multirow[t]{2}{*}{$\begin{array}{l}0.82 \\
(0.57- \\
1.18)\end{array}$} \\
\hline & dacarbazine monotherapy & & & 63 & 59 & $\begin{array}{l}50 \cdot 0 \\
(21.0- \\
82.0)\end{array}$ & $\begin{array}{l}4 \\
(63)\end{array}$ & \\
\hline \multirow[t]{2}{*}{$\begin{array}{l}\text { robert } 2013 \\
\text { (NCT00936221) }\end{array}$} & selumetinib+dacarbazine & $\begin{array}{l}\text { double- } \\
\text { blind }\end{array}$ & 2 & 45 & 49 & $\begin{array}{l}57.0 \\
(48.0- \\
69.0)\end{array}$ & $\begin{array}{l}18 \\
(45)\end{array}$ & \multirow[t]{2}{*}{$\begin{array}{l}0.93 \\
(0.67- \\
1.28)\end{array}$} \\
\hline & dacarbazine+placebo & & & 46 & 61 & $\begin{array}{l}52.0 \\
(40.0- \\
65.0)\end{array}$ & $\begin{array}{l}12 \\
(46)\end{array}$ & \\
\hline
\end{tabular}

\section{The risk of bias}

The risk of bias of the 8 RCTs was estimated by Mr. Yang and Mrs. Zhong. These studies had a low risk of detection, reporting and attrition bias. These RCTs at least double-blind except 3 trials (COMBI-v, BRIM-3, BREAK-3) were considered to have a high quality of evidence. 


\section{Outcomes}

\section{Objective response rate}

Due to the DICs of the random model and fixed model was $31.47,30.16$, respectively, we chose the fixed model to conducted the NMA. The result of the NMA showed in table 2. Combination atezolizumab with cobimetinib and vemurafenib was the most effective treatment in all treatments, despite the OR compared to combination vemurafenib and cobimetinib (OR: 1.1; Cl: 0.73-1.5) and combination pembrolizumab with dabrafenib and trametinib (OR: 2.1 ; Cl: 0.80-5.8) and combination dabrafenib and trametinib (OR: 1.4; Cl: 0.80-2.6) did not achieve statistical significance. Combination vemurafenib and cobimetinib was more effective than other treatments except combination atezolizumab with cobimetinib and vemurafenib, despite the OR compared to combination pembrolizumab with dabrafenib and trametinib (OR: 2.0; Cl: 0.82-5.1) and combination dabrafenib and trametinib (OR: 1.4; Cl: 0.86-2.2) did not achieve statistical significance. Combination pembrolizumab with trametinib and dabrafenib was more effective than combination dacarbazine and selumetinib, dabrafenib monotherapy (OR: 1.2; Cl: 0.51-2.9), vemurafenib monotherapy (OR: 1.2; $\mathrm{Cl}: 0.50-2.6$ ), dacarbazine monotherapy. Combination dabrafenib and trametinib was more effective than combination dacarbazine and selumetinib, dabrafenib monotherapy, vemurafenib monotherapy and dacarbazine monotherapy.

Table. 2 Results of objective response rate and overall survival

\begin{tabular}{|c|c|c|c|c|c|c|c|}
\hline \multirow{3}{*}{$\begin{array}{l}\text { Vemurafenib+ } \\
\text { Cobimetinib+ } \\
\text { atezolizumab }\end{array}$} & \multicolumn{7}{|c|}{ Overall survival (OS) } \\
\hline & 0.85 & 1.3 & 0.84 & 0.52 & 0.62 & 0.59 & 0.49 \\
\hline & $(0.64,1.1)$ & $(0.68,2.6)$ & $(0.55,1.3)$ & $(0.31,0.89)$ & $(0.39,0.98)$ & $(0.41,0.86)$ & $(0.32,0.74)$ \\
\hline 1.1 & Vemurafenib+ & 1.6 & 0.99 & 0.62 & 0.73 & 0.70 & 0.57 \\
\hline$(0.73,1.5)$ & cobimetinib & $(0.85,2.9)$ & $(0.71,1.4)$ & $(0.40,0.96)$ & $(0.51,1.1)$ & $(0.55,0.90)$ & $(0.42,0.78)$ \\
\hline 2.1 & 2.0 & Dabrafenib+ & 0.64 & 0.40 & 0.47 & 0.45 & 0.37 \\
\hline$(0.80,5.8)$ & $(0.82,5.1)$ & $\begin{array}{l}\text { Trametinib+ } \\
\text { pembrolizumab }\end{array}$ & $(0.38,1.1)$ & $(0.21,0.77)$ & $(0.27,0.82)$ & $(0.26,0.79)$ & $(0.21,0.66)$ \\
\hline 1.4 & 1.4 & 0.68 & Dabrafenib+ & 0.62 & 0.74 & 0.71 & 0.58 \\
\hline$(0.80,2.6)$ & $(0.86,2.2)$ & $(0.31,1.5)$ & Trametinib & $(0.41,0.95)$ & $(0.59,0.92)$ & $(0.56,0.88)$ & $(0.45,0.75)$ \\
\hline 21 & 20 & 10 & 15 & Dacarbazine+ & 1.2 & 1.1 & 0.93 \\
\hline$(6.5,70)$ & $(6.5,70)$ & $(2.6,38)$ & $(4.9,44)$ & selumetinib & $(0.78,1.8)$ & $(0.78,1.6)$ & $(0.67,1.3)$ \\
\hline 2.6 & 2.5 & 1.2 & 1.8 & 0.12 & dabrafenib & 0.96 & 0.79 \\
\hline$(1.3,5.2)$ & $(1.4,4.5)$ & $(0.51,2.9)$ & $(1.2,2.6)$ & $(0.040,0.37)$ & & $(0.73,1.3)$ & $(0.60,1.0)$ \\
\hline 2.5 & 2.3 & 1.2 & 1.7 & 0.12 & 0.95 & vemurafenib & 0.82 \\
\hline$(1.5,4.2)$ & $(1.6,3.4)$ & $(0.50,2.6)$ & $(1.3,2.3)$ & $(0.040,0.34)$ & $(0.60,1.5)$ & & $(0.68,0.98)$ \\
\hline 41 & 39 & 19 & 28 & 1.9 & 16 & 16 & dacarbazine \\
\hline$(19,90)$ & $(20,78)$ & $(7.1,52)$ & $(16,53)$ & $(0.79,4.8)$ & $(8.4,31)$ & $(9.6,30)$ & \\
\hline
\end{tabular}

\section{Overall survival}

Due to the DICs of the random model and fixed model was $15.06,14.13$, respectively, we chose the fixed model to conducted the NMA. The result of the NMA showed in table 2 .

Combination pembrolizumab with trametinib and dabrafenib seemed the most effective treatment, despite the HR compared to combination atezolizumab with cobimetinib (HR: 0.76 ; $\mathrm{Cl}: 0.39-1.5)$ and combination vemurafenib and cobimetinib (HR: 0.64 ; Cl: $0.35-1.2)$ and combination dabrafenib and trametinib (HR: 0.64; $\mathrm{Cl}$ : 0.38-1.1) did not achieve statistical significance in table 2. Combination atezolizumab with cobimetinib 
and vemurafenib seemed the second effective treatment, despite the HR compared to combination vemurafenib and cobimetinib (HR: 0.85 ; $\mathrm{Cl}$ : 0.64-1.1) and combination dabrafenib and trametinib (HR: 0.84; Cl: 0.55-1.3) did not achieve statistical significance. Combination vemurafenib and cobimetinib seemed the third effective treatment, despite the HR compared to combination dabrafenib and trametinib (HR: 0.99; Cl:0.711.4) and dabrafenib monotherapy (HR: 0.73; Cl:0.51-1.1) did not achieve statistical significance in table 2. Combination dabrafenib and trametinib was more effective than combination dacarbazine and selumetinib, dabrafenib monotherapy, vemurafenib monotherapy and dacarbazine monotherapy.

\section{Ranking}

Ranking analysis for ORR performed with SUCRA suggested that combination atezolizumab with cobimetinib and vemurafenib had the highest probability to rank at the first place for ORR (0.59), combination vemurafenib and cobimetinib ranked at the second place for ORR (0.57), combination dabrafenib and trametinib ranked at the third place for ORR (0.72), combination pembrolizumab with trametinib and dabrafenib ranked at the fourth place for ORR (0.39) (figure 2). Ranking analysis for OS performed with SUCRA suggested that combination pembrolizumab with trametinib and dabrafenib had the highest probability to rank at the first place for OS (0.78), combination atezolizumab with cobimetinib and vemurafenib ranked at the second place for OS (0.54), combination vemurafenib and cobimetinib ranked at the third place for OS (0.45), combination dabrafenib and trametinib ranked at the fourth place for OS (0.47) (figure 3 ).

\section{Discussion}

In the constant upgrading process of the treatment regimens for unresected stage III or metastatic stage IV BRAF mutant melanoma patients, monotherapy, due to high drug resistance, gradually replaced by double combination therapy.[41] And the combination MEK inhibitors and BRAF inhibitors appears to be the best treatment for BRAF V600 mutant melanoma patients.[42] Then, a previous network meta-analysis including an update to November 2018 of treatments for these special melanoma patients compared various double combination therapy and monotherapy.[43] That NMA showed that combination dabrafenib with trametinib seemed to be the best treatment for PFS while combination nivolumab with ipilimumab seemed to be the best treatment for OS. That NMA also showed that dacarbazine monotherapy seemed to be the worst treatment of these treatments, which was the same as ours.

Interestingly, we found an increased expression of PD-1 and PD-L1 in advanced or metastatic BRAF mutant melanoma patients who accept the treatment of BRAF inhibitors.[4] Pembrolizumab, as an anti-PD-1 immune checkpoint inhibitor, firstly estimated in KEYNOTE-001.[44] Until 2019, these data confirmed its durable antitumor activity in advanced melanoma.[45] In the second course of the phase III KEYNOTE-006,[46] the estimated 5-year survival outcome showed that pembrolizumab was more effective than ipilimumab in advanced and ipilimumab-naive melanoma patients. Atezolizumab, as an anti-PD-L1 immune checkpoint inhibitor, was originally used to cure lung and breast cancer patients alone or combined with other treatments. Then, atezolizumab monotherapy showed an ORR of 30\% in advanced melanoma.[47] Immune checkpoint inhibitors provide more durable responses but their response rates are relatively lower.[24] Therefore, a triple combination therapy of MEK inhibitors, BRAF inhibitors and anti-PD-1 or anti-PD-L1 immune checkpoint inhibitors need to be conducted.[25, 26] The first triple combination therapy was conducted in KEYNOTE-022 trials (combination pembrolizumab with dabrafenib and trametinib), which showed that the triple combination therapy was more effective than combination MEK inhibitors and BRAF inhibitors, though it has a higher rate of adverse events.[28] IMspire150 trials found that triple combination therapy (combination atezolizumab with cobimetinib and vemurafenib) was tolerable and safe, and vitally induced a better result of progression-free survival (PFS) in BRAF mutant melanoma patients.[27] Despite the overall survival in IMspire150 trials was not reached, the curves of overall survival began to separate indicated that the triple combination therapy was more effective which was the same as the delayed separation in KEYNOTE-022 trials.

Unlike previous NMA, our NMA included triple combination therapies like combination atezolizumab with cobimetinib and vemurafenib and combination pembrolizumab with trametinib and dabrafenib.[27, 28, 32] The two trials evaluated combination immune checkpoint therapy with MEK inhibitors and BRAF inhibitors in advanced or metastatic BRAF mutant melanomas. This NMA contained 8 phase 2 or 3 RCTs, with 3272 patients, and estimated the effectiveness of various first-line treatments for unresected stage III or metastatic stage IV melanoma patients (table 1). Additionally, our NMA carried out a complete search on PubMed and EMBASE updated to January 2021 with a low risk of bias. The results showed that combination atezolizumab with cobimetinib and vemurafenib was associated with the best ORR. Though not the best, combination pembrolizumab with trametinib and dabrafenib still showed considerable effectiveness for ORR. Combination pembrolizumab with trametinib and dabrafenib was associated with the best OS, and combination atezolizumab with cobimetinib and vemurafenib was the second for OS. According to the result of ORR and OS, these two combination treatments were likely to rank as the most appropriate treatments for unresected stage III or metastatic stage IV BRAF mutant melanoma patients.

\section{Limitations}


Although this NMA had no heterogeneity and absent inconsistency, it stills had limitations. First, the same as previous NMA,[43] ICls may be used in indolent melanoma patients, which limited the universality of our outcomes in all BRAF mutant patients. Second, our NMA for OS was based on $\mathrm{HR}$ and its $\mathrm{Cl}$, without consideration of survival curves, which need further research to perfect the results. Third, due to the only data, subgroup analysis could not be carried out by stratifying BRAR mutant melanoma patients by age, LDH levels, M1c stage, ECOG performance status, or other factors that may be associated with the results of the treatments. Fourth, the triple combination therapy, including IMspire150 trials and KEYNOTE-022 trials, are still ongoing. Fifth, with the sparseness information of treatment-related adverse events, we could not evaluate and rank the safety of these treatments. Therefore, more extensive researches are needed to conduct a comprehensive NMA.

\section{Conclusion}

The two triple combination therapies all show considerable effectiveness in all treatments. Combination atezolizumab with cobimetinib and vemurafenib has a higher ORR. Combination pembrolizumab with trametinib and dabrafenib show a better result in OS. In conclusion, the two triple combination therapies are more preferable for unresectable stage III or advanced (or metastatic) stage IV BRAF mutant melanoma patients.

\section{Declarations}

\section{Funding:}

This work was supported by grants from the National Natural Science Foundation of Liaoning Province (NO. 20180530081 to Chunli Wu) and Young and middle-aged scientific and technological talents support program of Shenyang City (NO. RC200554 to Chunli Wu).

\section{Conflict of Interest Disclosures:}

The authors declare that they have no conflict of interest.

\section{Availability of data and material:}

Not applicable

\section{Code availability:}

R Project for Statistical Computing; version 3.6.2; gemtc package

\section{Author Contributions:}

Mr. Yang had full access to all of the data in the study and take responsibility for the integrity of the data and the accuracy of the data analysis.

Concept and design: Yang.

Acquisition, analysis, or interpretation of data: All authors.

Drafting of the manuscript: Yang.

Critical revision of the manuscript for important intellectual content: Yang, Zhong, Wen.

Statistical analysis: Yang, Zhong.

Obtained funding: Wu.

Administrative, technical, or material support: Yang, Wen, Luo.

Supervision: Yang, Wu.

\section{References}


1. Davies H, Bignell GR, Cox C, Stephens P, Edkins S, Clegg S, Teague J, Woffendin H, Garnett MJ, Bottomley W et al: Mutations of the BRAF gene in human cancer. Nature 2002, 417(6892):949-954.http://doi.org/10.1038/nature00766

2. Curtin JA, Fridlyand J, Kageshita T, Patel HN, Busam KJ, Kutzner H, Cho KH, Aiba S, Brocker EB, LeBoit PE et al: Distinct sets of genetic alterations in melanoma. N Engl J Med 2005, 353(20):2135-2147.http://doi.org/10.1056/NEJMoa050092

3. Robert C, Grob JJ, Stroyakovskiy D, Karaszewska B, Hauschild A, Levchenko E, Chiarion Sileni V, Schachter J, Garbe C, Bondarenko I et al: Five-Year Outcomes with Dabrafenib plus Trametinib in Metastatic Melanoma. N Engl J Med 2019, 381(7):626636.http://doi.org/10.1056/NEJMoa1904059

4. Frederick DT, Piris A, Cogdill AP, Cooper ZA, Lezcano C, Ferrone CR, Mitra D, Boni A, Newton LP, Liu C et al: BRAF inhibition is associated with enhanced melanoma antigen expression and a more favorable tumor microenvironment in patients with metastatic melanoma. Clin Cancer Res 2013, 19(5):1225-1231.http://doi.org/10.1158/1078-0432.CCR-12-1630

5. Pelster MS, Amaria RN: Combined targeted therapy and immunotherapy in melanoma: a review of the impact on the tumor microenvironment and outcomes of early clinical trials. Ther Adv Med Oncol 2019, 11:1758835919830826.http://doi.org/10.1177/1758835919830826

6. Wilmott JS, Long GV, Howle JR, Haydu LE, Sharma RN, Thompson JF, Kefford RF, Hersey P, Scolyer RA: Selective BRAF inhibitors induce marked T-cell infiltration into human metastatic melanoma. Clin Cancer Res 2012, 18(5):1386-1394.http://doi.org/10.1158/10780432.CCR-11-2479

7. Ascierto PA, Dummer R: Immunological effects of BRAF+MEK inhibition. Oncoimmunology 2018, 7(9):e1468955.http://doi.org/10.1080/2162402X.2018.1468955

8. Long GV, Stroyakovskiy D, Gogas H, Levchenko E, de Braud F, Larkin J, Garbe C, Jouary T, Hauschild A, Grob JJ et al: Dabrafenib and trametinib versus dabrafenib and placebo for Val600 BRAF-mutant melanoma: a multicentre, double-blind, phase 3 randomised controlled trial. Lancet 2015, 386(9992):444-451.http://doi.org/10.1016/S0140-6736(15)60898-4

9. Kakadia S, Yarlagadda N, Awad R, Kundranda M, Niu J, Naraev B, Mina L, Dragovich T, Gimbel M, Mahmoud F: Mechanisms of resistance to BRAF and MEK inhibitors and clinical update of US Food and Drug Administration-approved targeted therapy in advanced melanoma. Onco Targets Ther 2018, 11:7095-7107.http://doi.org/10.2147/OTT.S182721

10. Larkin J, Ascierto PA, Dreno B, Atkinson V, Liszkay G, Maio M, Mandala M, Demidov L, Stroyakovskiy D, Thomas L et al: Combined vemurafenib and cobimetinib in BRAF-mutated melanoma. N Engl J Med 2014, 371(20):1867-

1876.http://doi.org/10.1056/NEJMoa1408868

11. Johnson DB, Flaherty KT, Weber JS, Infante JR, Kim KB, Kefford RF, Hamid O, Schuchter L, Cebon J, Sharfman WH et al: Combined BRAF (Dabrafenib) and MEK inhibition (Trametinib) in patients with BRAFV600-mutant melanoma experiencing progression with single-agent BRAF inhibitor. J Clin Oncol 2014, 32(33):3697-3704.http://doi.org/10.1200/JC0.2014.57.3535

12. Long GV, Stroyakovskiy D, Gogas H, Levchenko E, de Braud F, Larkin J, Garbe C, Jouary T, Hauschild A, Grob JJ et al: Combined BRAF and MEK inhibition versus BRAF inhibition alone in melanoma. N Engl J Med 2014, 371(20):1877-

1888.http://doi.org/10.1056/NEJMoa1406037

13. Schadendorf D, Long GV, Stroiakovski D, Karaszewska B, Hauschild A, Levchenko E, Chiarion-Sileni V, Schachter J, Garbe C, Dutriaux C et al: Three-year pooled analysis of factors associated with clinical outcomes across dabrafenib and trametinib combination therapy phase 3 randomised trials. Eur J Cancer 2017, 82:45-55.http://doi.org/10.1016/j.ejca.2017.05.033

14. O'Day SJ, Hamid O, Urba WJ: Targeting cytotoxic T-lymphocyte antigen-4 (CTLA-4): a novel strategy for the treatment of melanoma and other malignancies. Cancer 2007, 110(12):2614-2627.http://doi.org/10.1002/cncr.23086

15. Topalian SL, Hodi FS, Brahmer JR, Gettinger SN, Smith DC, McDermott DF, Powderly JD, Carvajal RD, Sosman JA, Atkins MB et al: Safety, activity, and immune correlates of anti-PD-1 antibody in cancer. N Engl J Med 2012, 366(26):2443-

2454.http://doi.org/10.1056/NEJMoa1200690

16. Wang C, Thudium KB, Han M, Wang XT, Huang H, Feingersh D, Garcia C, Wu Y, Kuhne M, Srinivasan M et al: In vitro characterization of the anti-PD-1 antibody nivolumab, BMS-936558, and in vivo toxicology in non-human primates. Cancer Immunol Res 2014, 2(9):846856.http://doi.org/10.1158/2326-6066.CIR-14-0040

17. Hodi FS, O'Day SJ, McDermott DF, Weber RW, Sosman JA, Haanen JB, Gonzalez R, Robert C, Schadendorf D, Hassel JC et al: Improved survival with ipilimumab in patients with metastatic melanoma. N Engl J Med 2010, 363(8):711-

723.http://doi.org/10.1056/NEJMoa1003466

18. Larkin J, Chiarion-Sileni V, Gonzalez R, Grob JJ, Cowey CL, Lao CD, Schadendorf D, Dummer R, Smylie M, Rutkowski P et al: Combined Nivolumab and Ipilimumab or Monotherapy in Untreated Melanoma. N Engl J Med 2015, 373(1):23-

34.http://doi.org/10.1056/NEJMoa1504030 
19. Robert C, Karaszewska B, Schachter J, Rutkowski P, Mackiewicz A, Stroiakovski D, Lichinitser M, Dummer R, Grange F, Mortier L et al: Improved overall survival in melanoma with combined dabrafenib and trametinib. N Eng/ J Med 2015, 372(1):30-

39.http://doi.org/10.1056/NEJMoa1412690

20. Robert C, Long GV, Brady B, Dutriaux C, Maio M, Mortier L, Hassel JC, Rutkowski P, McNeil C, Kalinka-Warzocha E et al: Nivolumab in previously untreated melanoma without BRAF mutation. N Eng/ J Med 2015, 372(4):320-330.http://doi.org/10.1056/NEJMoa1412082

21. Robert C, Schachter J, Long GV, Arance A, Grob JJ, Mortier L, Daud A, Carlino MS, McNeil C, Lotem M et al: Pembrolizumab versus Ipilimumab in Advanced Melanoma. N Eng/ J Med 2015, 372(26):2521-2532.http://doi.org/10.1056/NEJMoa1503093

22. Robert C, Thomas L, Bondarenko I, O'Day S, Weber J, Garbe C, Lebbe C, Baurain JF, Testori A, Grob JJ et al: Ipilimumab plus dacarbazine for previously untreated metastatic melanoma. N Engl J Med 2011, 364(26):2517-2526.http://doi.org/10.1056/NEJMoa1104621

23. Wolchok JD, Chiarion-Sileni V, Gonzalez R, Rutkowski P, Grob JJ, Cowey CL, Lao CD, Wagstaff J, Schadendorf D, Ferrucci PF et al: Overall Survival with Combined Nivolumab and Ipilimumab in Advanced Melanoma. N Engl J Med 2017, 377(14):1345-

1356.http://doi.org/10.1056/NEJMoa1709684

24. Khair DO, Bax HJ, Mele S, Crescioli S, Pellizzari G, Khiabany A, Nakamura M, Harris RJ, French E, Hoffmann RM et al: Combining Immune Checkpoint Inhibitors: Established and Emerging Targets and Strategies to Improve Outcomes in Melanoma. Front Immunol 2019, 10:453.http://doi.org/10.3389/fimmu.2019.00453

25. Hu-Lieskovan S, Mok S, Homet Moreno B, Tsoi J, Robert L, Goedert L, Pinheiro EM, Koya RC, Graeber TG, Comin-Anduix B et al: Improved antitumor activity of immunotherapy with BRAF and MEK inhibitors in BRAF(V600E) melanoma. Sci Trans/ Med 2015,

7(279):279ra241.http://doi.org/10.1126/scitranslmed.aaa4691

26. Ebert PJR, Cheung J, Yang Y, McNamara E, Hong R, Moskalenko M, Gould SE, Maecker H, Irving BA, Kim JM et al: MAP Kinase Inhibition Promotes T Cell and Anti-tumor Activity in Combination with PD-L1 Checkpoint Blockade. Immunity 2016, 44(3):609621.http://doi.org/10.1016/j.immuni.2016.01.024

27. Gutzmer R, Stroyakovskiy D, Gogas H, Robert C, Lewis K, Protsenko S, Pereira RP, Eigentler T, Rutkowski P, Demidov L et al: Atezolizumab, vemurafenib, and cobimetinib as first-line treatment for unresectable advanced BRAF(V600) mutation-positive melanoma (IMspire150): primary analysis of the randomised, double-blind, placebo-controlled, phase 3 trial. Lancet 2020, 395(10240):1835-

1844.http://doi.org/10.1016/S0140-6736(20)30934-X

28. Ascierto PA, Ferrucci PF, Fisher R, Del Vecchio M, Atkinson V, Schmidt H, Schachter J, Queirolo P, Long GV, Di Giacomo AM et al: Dabrafenib, trametinib and pembrolizumab or placebo in BRAF-mutant melanoma. Nat Med 2019, 25(6):941-946.http://doi.org/10.1038/s41591-0190448-9

29. Hutton B, Salanti G, Caldwell DM, Chaimani A, Schmid CH, Cameron C, Ioannidis JP, Straus S, Thorlund K, Jansen JP et al: The PRISMA extension statement for reporting of systematic reviews incorporating network meta-analyses of health care interventions: checklist and explanations. Ann Intern Med 2015, 162(11):777-784.http://doi.org/10.7326/M14-2385

30. J C, M C, J M, I B, (editors) WV: Cochrane Methods. Cochrane Database of Systematic Reviews 2016;(10 Supp/ 1) 2016.http://doi.org/10.1002/14651858.Cd201601

31. Chaimani A, Salanti G: Using network meta-analysis to evaluate the existence of small-study effects in a network of interventions. Res Synth Methods 2012, 3(2):161-176.http://doi.org/10.1002/jrsm.57

32. Ferrucci PF, Di Giacomo AM, Del Vecchio M, Atkinson V, Schmidt H, Schachter J, Queirolo P, Long GV, Stephens R, Svane IM et al: KEYNOTE022 part 3: a randomized, double-blind, phase 2 study of pembrolizumab, dabrafenib, and trametinib in BRAF-mutant melanoma. $J$ Immunother Cancer 2020, 8(2).http://doi.org/10.1136/jitc-2020-001806

33. Ascierto PA, McArthur GA, Dreno B, Atkinson V, Liszkay G, Di Giacomo AM, Mandala M, Demidov L, Stroyakovskiy D, Thomas L et al: Cobimetinib combined with vemurafenib in advanced BRAF(V600)-mutant melanoma (coBRIM): updated efficacy results from a randomised, double-blind, phase 3 trial. Lancet Onco/ 2016, 17(9):1248-1260.http://doi.org/10.1016/S1470-2045(16)30122-X

34. Long GV, Flaherty KT, Stroyakovskiy D, Gogas H, Levchenko E, de Braud F, Larkin J, Garbe C, Jouary T, Hauschild A et al: Dabrafenib plus trametinib versus dabrafenib monotherapy in patients with metastatic BRAF V600E/K-mutant melanoma: long-term survival and safety analysis of a phase 3 study. Ann Onco/ 2017, 28(7):1631-1639.http://doi.org/10.1093/annonc/mdx176

35. Long GV, Flaherty KT, Stroyakovskiy D, Gogas H, Levchenko E, de Braud F, Larkin J, Garbe C, Jouary T, Hauschild A et al: Dabrafenib plus trametinib versus dabrafenib monotherapy in patients with metastatic BRAF V600E/K-mutant melanoma: long-term survival and safety analysis of a phase 3 study. Ann Oncol 2019, 30(11):1848.http://doi.org/10.1093/annonc/mdz221

36. Chapman PB, Robert C, Larkin J, Haanen JB, Ribas A, Hogg D, Hamid O, Ascierto PA, Testori A, Lorigan PC et al: Vemurafenib in patients with BRAFV600 mutation-positive metastatic melanoma: final overall survival results of the randomized BRIM-3 study. Ann Oncol 2017, 28(10):2581-2587.http://doi.org/10.1093/annonc/mdx339 
37. Chapman PB, Hauschild A, Robert C, Haanen JB, Ascierto P, Larkin J, Dummer R, Garbe C, Testori A, Maio M et al: Improved survival with vemurafenib in melanoma with BRAF V600E mutation. N Engl J Med 2011, 364(26):2507-2516.http://doi.org/10.1056/NEJMoa1103782

38. Hauschild A, Grob JJ, Demidov LV, Jouary T, Gutzmer R, Millward M, Rutkowski P, Blank CU, Miller WH, Jr., Kaempgen E et al: Dabrafenib in BRAF-mutated metastatic melanoma: a multicentre, open-label, phase 3 randomised controlled trial. Lancet 2012, 380(9839):358365.http://doi.org/10.1016/S0140-6736(12)60868-X

39. Latimer NR, Abrams KR, Amonkar MM, Stapelkamp C, Swann RS: Adjusting for the Confounding Effects of Treatment Switching-The BREAK-3 Trial: Dabrafenib Versus Dacarbazine. Oncologist 2015, 20(7):798-805.http://doi.org/10.1634/theoncologist.2014-0429

40. Robert C, Dummer R, Gutzmer R, Lorigan P, Kim KB, Nyakas M, Arance A, Liszkay G, Schadendorf D, Cantarini M et al: Selumetinib plus dacarbazine versus placebo plus dacarbazine as first-line treatment for BRAF-mutant metastatic melanoma: a phase 2 double-blind randomised study. Lancet Onco/ 2013, 14(8):733-740.http://doi.org/10.1016/S1470-2045(13)70237-7

41. Devji T, Levine O, Neupane B, Beyene J, Xie F: Systemic Therapy for Previously Untreated Advanced BRAF-Mutated Melanoma: A Systematic Review and Network Meta-Analysis of Randomized Clinical Trials. JAMA Oncol 2017, 3(3):366-

373.http://doi.org/10.1001/jamaoncol.2016.4877

42. Pasquali S, Chiarion-Sileni V, Rossi CR, Mocellin S: Immune checkpoint inhibitors and targeted therapies for metastatic melanoma: A network meta-analysis. Cancer Treat Rev 2017, 54:34-42.http://doi.org/10.1016/j.ctrv.2017.01.006

43. Zoratti MJ, Devji T, Levine O, Thabane L, Xie F: Network meta-analysis of therapies for previously untreated advanced BRAF-mutated melanoma. Cancer Treat Rev 2019, 74:43-48.http://doi.org/10.1016/j.ctrv.2019.02.001

44. Robert C, Ribas A, Wolchok JD, Hodi FS, Hamid O, Kefford R, Weber JS, Joshua AM, Hwu WJ, Gangadhar TC et al: Anti-programmed-deathreceptor-1 treatment with pembrolizumab in ipilimumab-refractory advanced melanoma: a randomised dose-comparison cohort of a phase 1 trial. Lancet 2014, 384(9948):1109-1117.http://doi.org/10.1016/S0140-6736(14)60958-2

45. Hamid O, Robert C, Daud A, Hodi FS, Hwu WJ, Kefford R, Wolchok JD, Hersey P, Joseph R, Weber JS et al: Five-year survival outcomes for patients with advanced melanoma treated with pembrolizumab in KEYNOTE-001. Ann Oncol 2019, 30(4):582-

588.http://doi.org/10.1093/annonc/mdz011

46. Robert C, Ribas A, Schachter J, Arance A, Grob JJ, Mortier L, Daud A, Carlino MS, McNeil CM, Lotem M et al: Pembrolizumab versus ipilimumab in advanced melanoma (KEYNOTE-006): post-hoc 5-year results from an open-label, multicentre, randomised, controlled, phase 3 study. Lancet Oncol 2019, 20(9):1239-1251.http://doi.org/10.1016/S1470-2045(19)30388-2

47. Hamid O, Molinero L, Bolen CR, Sosman JA, Munoz-Couselo E, Kluger HM, McDermott DF, Powderly JD, Sarkar I, Ballinger M et al: Safety, Clinical Activity, and Biological Correlates of Response in Patients with Metastatic Melanoma: Results from a Phase I Trial of Atezolizumab. Clin Cancer Res 2019, 25(20):6061-6072.http://doi.org/10.1158/1078-0432.CCR-18-3488

\section{Figures}




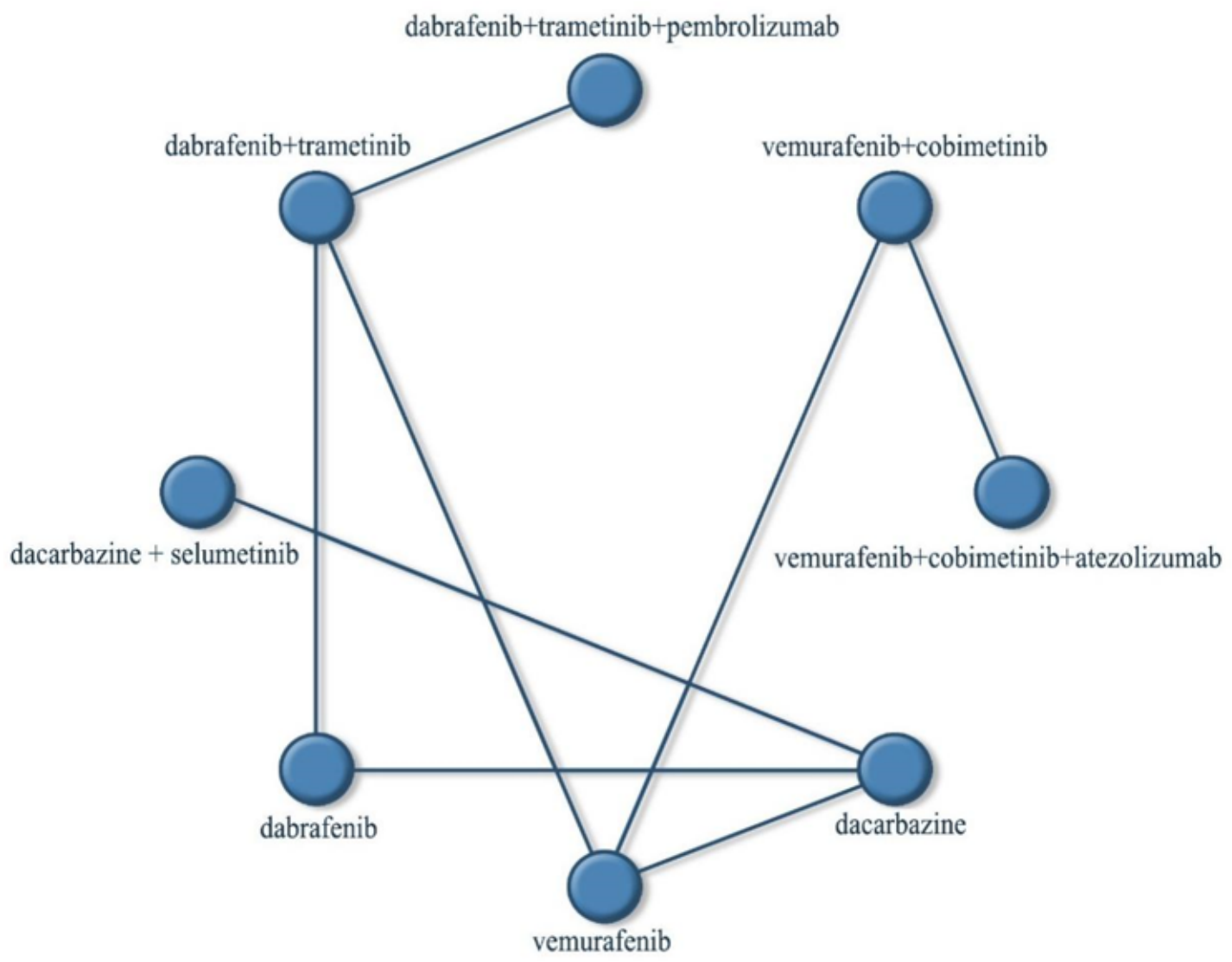

Figure 1

Network of evidence for objective response rate and overall survival 


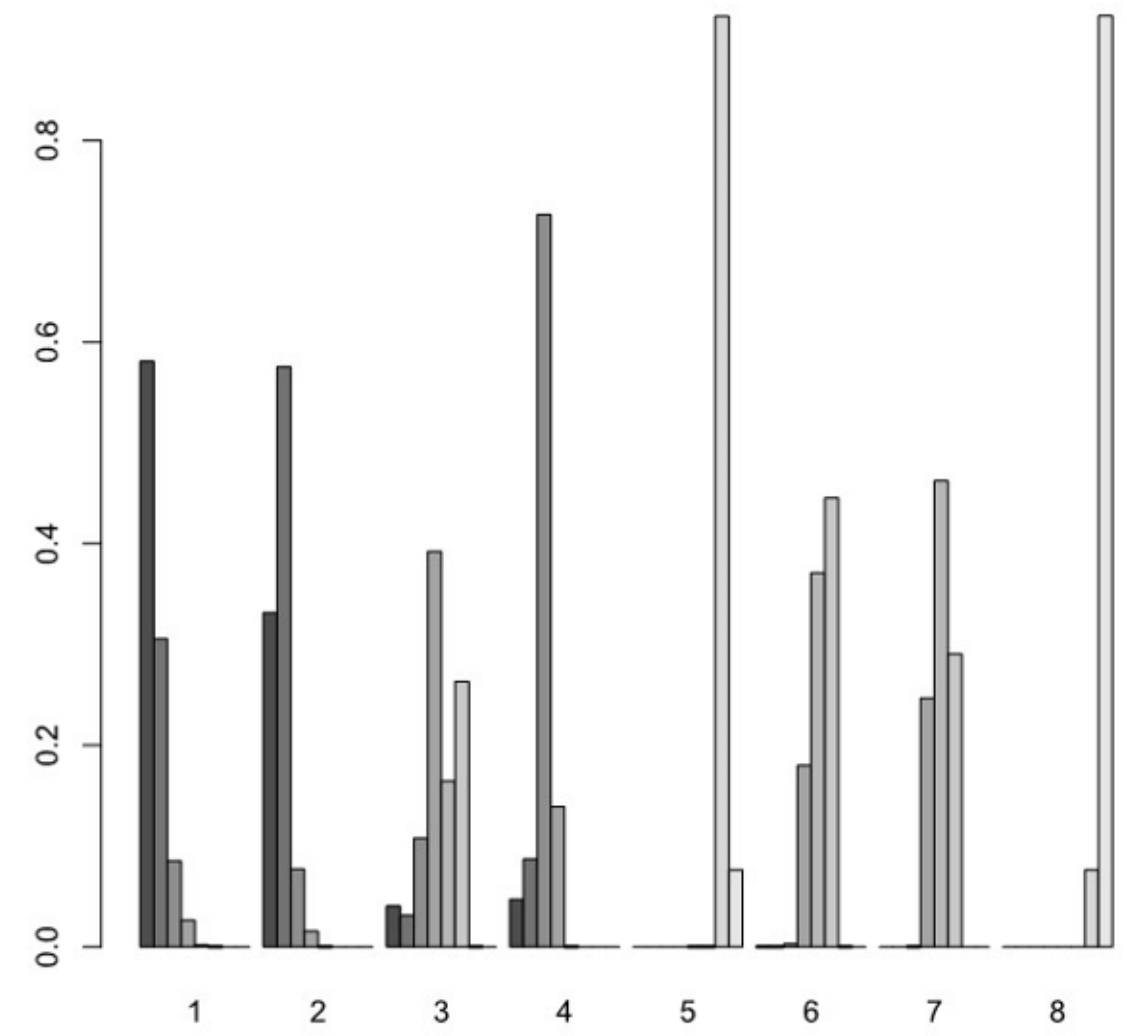

Figure 2

Ranking analysis for objective response rate

Page 12/13 


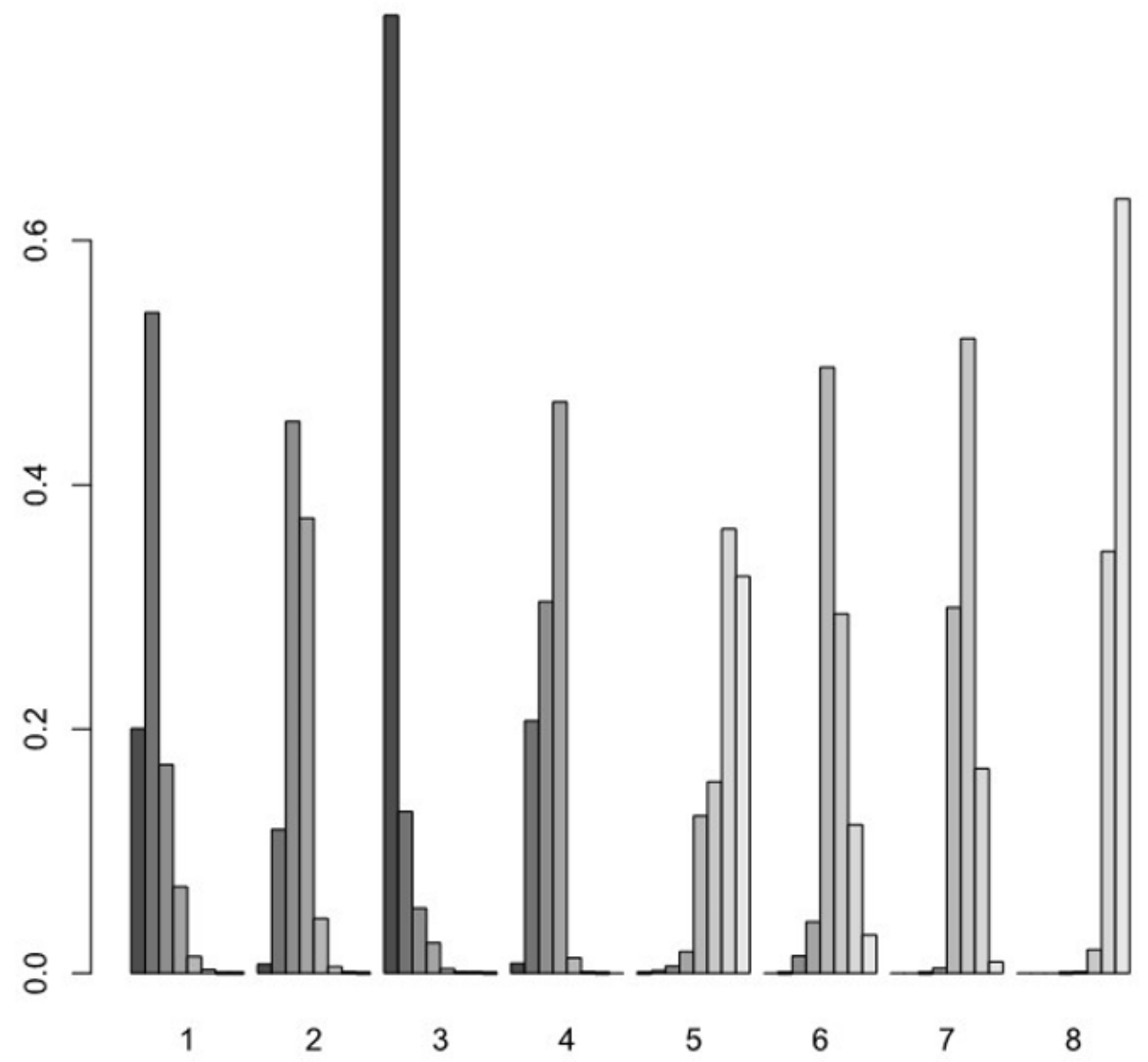

Figure 3

Ranking analysis for overall survival

\section{Supplementary Files}

This is a list of supplementary files associated with this preprint. Click to download.

- PRISMA2009ChecklistMSWord.doc

- PRISMA2009FlowDiagramMSWord.doc 